\title{
The effects of UV-C treatment on the quality of orange, carrot and celery juice blend
}

\author{
Nik Nornisa, Chandran Somasundram*, Zuliana Razali \\ Biotechnology Division, Institute of Biological Sciences, University of Malaya, Malaysia
}

\begin{abstract}
Juice blend is first becoming the preferred choice of beverage due to it high nutritional quality. However, current methods that are used in the processing of juice products, such as thermal treatments, has been reported significantly reduces nutritional quality. UV-C treatment is an alternative method that could extend the shelf life as well as maintain the quality of juice. In this study, the quality attributes of the juice blend upon exposure to ultraviolet light and thermal treatment were studied. Freshly squeezed orange, carrot and celery juice blend was exposed to ultraviolet light (for 15,30 , and 60 minutes) and thermal pasteurization $\left(a t 90^{\circ} \mathrm{C}\right.$, for $30 \mathrm{~s}$ and 60 s). Microbial analysis, physicochemical properties, antioxidant activity as well as other quality parameters were carried out on all samples. The results showed no significant difference in physicochemical properties among all samples studied. Nevertheless, a significant increase was observed in polyphenol content, antioxidant capacity, and flavonoid content in samples treated with UV-C compared to control and thermal treated. Moreover, juice blend exposed to UV-C treatment (30 and 60 minutes) showed increase in extractability of carotenoids. UV-C treated samples also exhibited reduction in microbial load and prolonged shelf life. The results obtained support the use of $\mathrm{UV}-\mathrm{C}$ as an alternative to thermal treatment in improving the quality of juice blend.
\end{abstract}

Keywords: UV-C treatment, Nutritious food, Pasteurization, Spoilage enzymes.

Accepted on October 08, 2018

\section{Introduction}

Higher demand from consumers for functional and nutritious food has led to the processing of mixed fruit and vegetable juices, otherwise known as juice blend [1]. The consumption of juice blend has been associated with higher nutrient and fibre intake as well as antioxidant and anti-inflammatory properties [2]. One of the most popular juices is a mix of carrot and orange mainly because of its attractive colour and balanced taste. Celery as a stand-alone vegetable is the most extensively consumed vegetable available in the market and is appreciated as it is an excellent source of nutrition especially Vitamin $\mathrm{K}$ and molybdenum [3]. The addition of celery into carrot and orange juice blends increases total nutrition and helps improve palatability as the flavour from orange and carrot helps diminish the bitter taste of celery.

Currently, thermal pasteurization is the most preferred method for processing food due to its ability to inactivate microorganisms and food spoilage enzymes, therefore extending the shelf life of juices [4]. However, due to high heat exposure, thermal treatment can negatively affect the food product quality, causing several chemical and physical changes which lowers the bioavailability of some bioactive compounds such as ascorbic acid [4-6]. Nonthermal processing has been explored for its efficacy to extend shelf life and enhance safety of fresh juice while preserving nutritional qualities. UV-C light with a peak emission at 254 $\mathrm{nm}$ exhibits germicidal effect against microorganisms such as bacteria, viruses, yeasts and moulds [7]. Furthermore, contrary to heat treatments, the use of UV-C has been reported to cause minimal damage to the physicochemical and nutritional quality of juice [8]. This study aims to compare the quality of thermal and UV-C treated juice blend. Analysis will include shelf life studies as well as physicochemical and antioxidant analysis.

\section{Materials and Methods}

\section{Preparation of juice blend}

Orange, carrot and celery, free from external defects were purchased from a local supermarket in Kuala Lumpur, Malaysia. Fruits and vegetables were washed with sterile distilled water. Washed fruits and vegetable were cut and where necessary, seeds were discarded. All cut fruits and vegetables were blended using a household juice blender (Philips Juice Extractor HR 2820). Each extracted juice was then filtered using a plastic sieve with a diameter of $2 \mathrm{~mm}$ to remove any remaining pulp or fibre. The filtered orange, carrot and celery juice were mixed with a ratio of 1:1:0.1. For comparative purposes, an untreated sample was similarly retained and assayed.

\section{Thermal treatment and $U V$-C treatment}

The juice blend was heated in a water bath (Memmert, Germany) at $90^{\circ} \mathrm{C}$ for $30 \mathrm{~s}$ (mild heat pasteurization) and $60 \mathrm{~s}$ (high heat pasteurization). The temperature of the juice samples were regularly monitored at the centre of the boiling tube using a thermometer. The measurement time was taken when the juice samples reached the target temperature. After thermal treatment, the juice samples were cooled down by immersing in an ice water bath. The juice samples were exposed to UV-C light under batch conditions. The juice sample was poured into 
sterile Petri dishes and then exposed to germicidal UV-C light in a laminar flow cabinet (Gelman Science Biological Safety Cabinet Class II, NSW, Australia). The duration of exposure of UV-C light was 15, 30 and 60 minutes. The following terms were used to describe the different treatments in this study: control (untreated sample); T30 (thermal treatment for 30 seconds); T60 (thermal treatment for 60 seconds); UV15 (UV$\mathrm{C}$ treatment for 15 minutes); UV30 (UV-C treatment for 30 minutes); UV60 (UV-C treatment for 60 minutes).

\section{Microbial inactivation analysis}

Control, thermal treated, and UV-C treated juice blend were filled into sterile glass bottles. The bottles were capped tightly and stored in fridge at $4 \pm 1^{\circ} \mathrm{C}$ for 13 days. Microbial count of juice blend samples was analysed right after treatment (day 0 ) and after storage for 13 days. The microbial count for juice samples were determined using 3M Petrifilm plates (3M Centre, MN, USA) for aerobic bacteria according to the method by Santhirasegaram, et al. [9]. The aerobic bacteria were calculated as colony forming units (CFU) per millilitre of juice using the following equation:

$$
\mathrm{CFU} / \mathrm{ml}=\frac{(\text { number of colonies } \mathrm{x} \text { dilution factor of plate) }}{\text { aliquot plated }}
$$

\section{Physicochemical analysis (pH, total soluble solids and titratable acidity)}

The $\mathrm{pH}$ of the juice samples was determined using a $\mathrm{pH}$ meter (Hanna Microprocessor pH 211, Italy). Total soluble solids were determined using a digital refractometer (Atago PR-1 digital refractometer). Results were expressed in standard ${ }^{\circ}$ Brix unit. Determination of titratable acidity was carried out according to the method by Sadler \& Murphy, (2010). The titratable acidity was calculated using the following formula:

$\% \mathrm{TA}=\frac{\mathrm{V} 1 \times 0.1 \mathrm{~N} \mathrm{NaOH} \times \text { eq. of wt. in acid X } 100}{\mathrm{~V} 2 \times 1000}$

Where V1 is volume of titrant (ml), Eq. of wt. in acid is equivalent of weight of anhydrous citric acid $(64 \mathrm{mg} / \mathrm{mEq})$ and $\mathrm{V} 2$ is volume of sample $(\mathrm{ml})$.

\section{Clarity and non-enzymatic browning index (NEBI)}

The clarity of juicewas determined by measuring the transmittance of supernatant at $660 \mathrm{~nm}$ using a spectrophotometer, based on the method by Glevitzky, et al. [10]. High percentage of transmittance at $660 \mathrm{~nm}$ corresponds to high clarity. NEBI was carried out based on the method by Cohen, et al. [11].

\section{Ascorbic acid content}

The ascorbic acid content in juice samples was determined using the 2,6-dichlorophenol-indophenol (DCPIP) visual titration method by Ranganna [12]. Diluted juice sample was filtered using Whatman No.1 filter paper. Then, the filtrate was titrated with standardized dye solution to a pink end point. Results obtained were expressed as milligram of ascorbic acid per 100 $\mathrm{ml}$ of sample, using the following equation:

Ascorbic acid content $=\frac{\mathrm{V} 1 \times \text { dye factor } \times \mathrm{V} 2 \times 100}{\mathrm{~S} 1 \times \mathrm{S} 2}$
Where V1 is titre ( $\mathrm{ml}), \mathrm{V} 2$ is volume made up $(\mathrm{ml}), \mathrm{S} 1$ is aliquot of extract taken for estimation ( $\mathrm{ml})$, and $\mathrm{S} 2$ is volume of sample taken for estimation $(\mathrm{ml})$

\section{Total carotenoid content}

Carotenoid was extracted using the method by Lee, et al. [13]. The total carotenoid content was determined according to Scott [14]. Absorbance of extracted hexane was measured at $450 \mathrm{~nm}$. The total carotenoid content using $\beta$-carotene as a reference was calculated using the following formula:

Total carotenoid content $=\left(A \times V_{1} \times C^{1 \%}\right) /\left(A^{1 \%}\right)$

Where $A$ is absorbance reading of the diluted sample, $V_{1}$ is dilution factor, $\mathrm{A}^{1 \%}$ is absorbance of a $1 \%$ solution (the extinction coefficient for $\beta$-carotene: $2592 \mathrm{AU})$, and $\mathrm{C}^{1 \%}$ is concentration of a $1 \%$ solution $(10 \mathrm{mg} / \mathrm{ml})$.

\section{Antioxidant activity}

Preparation of extract: The antioxidant extraction was performed based on $\mathrm{Xu}$, et al. with slight modifications [15]. Juice blend sample was added to $80 \%$ methanol with a ratio of $1: 1$ to purify the sample. The mixture was placed in a rotary shaker (Orbital Shaker S01, Stuart) for 30 minutes at room temperature, and then centrifuged (UEC Micro). The supernatant was used for antioxidant analysis.

Total polyphenol content (TPC): Total polyphenol content of juice samples was determined using Folin-Ciocalteu assay modified to a microscale [16]. A standard curve of gallic acid $\left(\mathrm{y}=0.0056 \mathrm{x}, \mathrm{r}^{2}=0.9955\right)$ was prepared, and the results were expressed as milligrams of gallic acid equivalent (GAE) per 100 $\mathrm{ml}$ of juice samples.

1,1-Di-phenyl-2-picrylhydrazyl (DPPH) radical scavenging assay: DPPH assay was carried out based on the method by Bae and Suh [16]. A standard curve of ascorbic acid $(y=10.145 x$, $\left.r^{2}=0.9907\right)$ was prepared and results were reported as micrograms of ascorbic acid equivalent (AAE) per ml juice extract.

The radical scavenging activity was then calculated using following equation:

$\%$ DPPH Inhibition $=\left(\mathrm{A}_{\text {control }}-\mathrm{A}_{\text {sample }} / \mathrm{A}_{\text {control }}\right) \times 100$

Where $\mathrm{A}_{\text {control }}=$ absorbance reading of control and $\mathrm{A}_{\text {sample }}=$ absorbance reading of sample

Total antioxidant capacity (TAC): Total antioxidant activity in juice samples was determined based on phosphomolybdenum method by Prieto, et al. [17]. A standard curve of ascorbic acid $\left(\mathrm{y}=0.0018 \mathrm{x}, \mathrm{r}^{2}=0.9981\right)$ was prepared and the results were reported as micrograms of ascorbic acid equivalent (AAE) per ml juice extract.

Total flavonoid content (TFC): The total flavonoid content was determined based on the colorimetric method described by Sakanaka, et al. [18]. A standard curve of catechin $(y=0.0135 x$, $\mathrm{r}^{2}=0.9943$ ) was prepared. Results were reported as milligrams of catechin equivalent (CE) per $100 \mathrm{ml}$ juice sample.

\section{Sensory analysis}

Consumer's acceptance test was carried out at a laboratory 
(University of Malaya) by 30 untrained panellists. Six bottles of samples were prepared and labelled randomly as A, B C, D, E, and F. Each panellist was given a plastic spoon to taste the samples. Water and crackers were served for cleansing the palate between samples. Panellists evaluated appearance, odour, flavour, sweetness, acidity and overall acceptability using a 1-5 scale, with 1 corresponding to "much dislike" and 5 to "like a lot'.

\section{Statistical analysis}

All data was subjected to statistical analysis using SPSS Software (SPSS Inc, IBM). The experimental treatments were compared using a one-way analysis of variance. Significant differences $(p<0.05)$ between treatment means were determined by Tukey's HSD (Honestly Significant Difference) test.

\section{Results and Discussion}

\section{Microbial inactivation analysis (aerobic plate count)}

The shelf life of juice samples was evaluated according to the Institute of Food Science and Technology, IFST (1999). The acceptable maximum microbial load in fruit juices is $4 \log \mathrm{CFU} /$ $\mathrm{ml}$. The aerobic bacteria count in freshly squeezed juice blend was $3.42 \log \mathrm{CFU} / \mathrm{ml}$, while thermal treated and UV-C treated samples showed no colony counts (Table 1). Both treatments successfully reduced aerobic bacteria counts to below detection limits with UV60 exhibiting the most effective microbial load reduction among UV treatments. After day 7, untreated juice exceeded the acceptable microbial load. On the contrary, all treated samples maintained microbial load below 4 log CFU/ml throughout 13 days of storage with T60 and UV60 recording the lowest count. This could be a consequence of the denaturation of organic molecules necessary for proper functioning of microbial cells by high temperature, thus causing cellular death while absorption of UV-C by microbial DNA or RNA structures results in the formation of pyrimidine dimers which stops microorganisms from replicating, thus inactivating microbial growth [1]. Nevertheless, shorter exposure to UV-C was not as efficient in eliminating microbial growth as aerobic count was detected by day 7 . Our results are consistent with other findings where a longer exposure to UV-C resulted in greater reduction of microbial load [8].

\section{Physicochemical analysis (pH, TSS, and TA)}

No significant difference in $\mathrm{pH}$ was observed in samples after treatment as well as after storage for 7 days (Table 2). This is agreeable with studies by Bull, et al. and Pala and Toklucu, who observed no significant alterations in $\mathrm{pH}$ of juice processed with heat pasteurization $[5,19]$. A slight decrease in $\mathrm{pH}$ after storage may result from organic acids released due to breakdown of dissolved particulates. In contrast, a significant difference in TSS was observed in all treated samples compared to control, except UV15. Similar to the findings of Chia, et al. [20], the TSS value of UV-C radiated juice was lower than heat pasteurized juice throughout storage for 13 weeks. The same trend was also observed in titratable acidity (TA), where UV-C treated juice showed lower TA value compared to thermal pasteurized juice throughout storage for 7 days. The changes in TSS and TA may be explained by the presence of microorganism in juices that cause deterioration of fruit juice as a result of sugar fermentation [21].

\section{Clarity and NEBI}

Clarity acts as an indicator for turbidity level or darkening of fruit juices. Thermal treated samples showed the lowest clarity with a $48 \%$ reduction compared to control (Table 3 ). When heat is applied to juice samples, the juice particle becomes larger and colloidal materials will consequently clot $[22,23]$, which will then contribute to the increasing viscosity of juice. In addition, high viscosity of juice may also be contributed by the swelling of particles and infiltration of water between cellulose chains during heating process [23]. Furthermore, during thermal pasteurization of juices, cell wall is greatly ruptured which leads to leakage of soluble pectin out from the cell walls. This leads to highly concentrated pectin colloidal solution [24,25]. Increased viscosity and pectin concentration contributes to decrease of

Table 1. Effects of thermal treatment and UV-C treatment on aerobic bacteria count of juice blend.

\begin{tabular}{|c|c|c|c|}
\hline \multirow{2}{*}{ Treatment } & \multicolumn{2}{|c|}{ Log of Colony Forming Units per ml of juice (CFU/ml) } \\
\cline { 2 - 4 } & Day 0 & Day 7 & Day 13 \\
\hline Control & $3.42 \pm 0.085^{\mathrm{b}}$ & $3.96 \pm 0.024^{\mathrm{a}}$ & $>4.00^{\mathrm{a}}$ \\
\hline T30 & $\mathrm{ND}^{\mathrm{a}}$ & $\mathrm{ND}^{\mathrm{b}}$ & $3.56 \pm 0.057^{\mathrm{cd}}$ \\
\hline T60 & $\mathrm{ND}^{\mathrm{a}}$ & $\mathrm{ND}^{\mathrm{b}}$ & $3.20 \pm 0.141^{\mathrm{bc}}$ \\
\hline UV15 & $\mathrm{ND}^{\mathrm{a}}$ & $3.46 \pm 0.123^{\mathrm{a}}$ & $3.86 \pm 0.028^{\mathrm{e}}$ \\
\hline UV30 & $\mathrm{ND}^{\mathrm{a}}$ & $3.00 \pm 1.414^{\mathrm{b}}$ & $3.75 \pm 0.038^{\mathrm{de}}$ \\
\hline UV60 & $\mathrm{ND}^{\mathrm{a}}$ & $\mathrm{ND}^{\mathrm{b}}$ & $3.36 \pm 0.085^{\mathrm{c}}$ \\
\hline Values followed by different letters within the same column are significantly different $(\mathrm{p}<0.05)(\mathrm{n}=9)$. & \\
\hline
\end{tabular}

Table 2. Effects of thermal treatment and UV-C treatment on physicochemical properties ( $\mathrm{pH}$, total soluble solids and titratable acidity) of juice blend.

\begin{tabular}{|c|c|c|c|c|c|c|}
\hline \multirow[t]{2}{*}{ Samples } & \multicolumn{2}{|c|}{$\mathrm{pH}$} & \multicolumn{2}{|c|}{ TSS } & \multicolumn{2}{|c|}{ TA } \\
\hline & DAY 0 & DAY 7 & DAY 0 & DAY 7 & DAY 0 & DAY 7 \\
\hline Control & $3.88 \pm 0.017^{a}$ & $3.82 \pm 0.02^{\mathrm{a}}$ & $8.2 \pm 0^{\mathrm{a}}$ & $8.9 \pm 0.141^{b c}$ & $0.48 \pm 0.022^{b}$ & $0.37 \pm 0.005^{b}$ \\
\hline T30 & $3.84 \pm 0.016^{a}$ & $3.83 \pm 0.02^{\mathrm{a}}$ & $8.97 \pm 0.047^{c}$ & $9.23 \pm 0.205^{c}$ & $0.41 \pm 0.005^{a}$ & $0.74 \pm 0.016^{b}$ \\
\hline T60 & $3.87 \pm 0.005^{\mathrm{a}}$ & $3.86 \pm 0.03^{a}$ & $8.77 \pm 0.047^{\mathrm{bc}}$ & $8.93 \pm 0.125^{b c}$ & $0.39 \pm 0.022^{a}$ & $0.72 \pm 0.012^{\mathrm{b}}$ \\
\hline UV15 & $3.83 \pm 0.02^{\mathrm{a}}$ & $3.81 \pm 0.03^{a}$ & $8.4 \pm 0.245^{\mathrm{ab}}$ & $8.6 \pm 0.141^{a b}$ & $0.44 \pm 0.019^{a b}$ & $0.37 \pm 0.009^{a}$ \\
\hline UV30 & $3.84 \pm 0.04^{\mathrm{a}}$ & $3.75 \pm 0.02^{a}$ & $8.73 \pm 0.205^{b c}$ & $8.4 \pm 0.094^{\mathrm{ab}}$ & $0.4 \pm 0.014^{a}$ & $0.37 \pm 0.009^{a}$ \\
\hline UV60 & $3.84 \pm 0.05^{a}$ & $3.78 \pm 0.107^{a}$ & $8.87 \pm 0.125^{b c}$ & $8.3 \pm 0.170^{a}$ & $0.39 \pm 0.009^{a}$ & $0.37 \pm 0.012^{\mathrm{a}}$ \\
\hline
\end{tabular}


Citation: Nornisa N, Somasundram C, Razali Z. The effects of UV-C treatment on the quality of orange, carrot and celery juice blend. J Food Sci Nutr. 2018;1(3):1-7.

Table 3. Effects of thermal treatment and UV-C treatment on clarity and non-enzymatic browning index of juice blend.

\begin{tabular}{|c|c|c|c|c|}
\hline \multirow[t]{2}{*}{ Samples } & \multicolumn{2}{|c|}{ Clarity } & \multicolumn{2}{|c|}{ NEBI } \\
\hline & DAY 0 & DAY 7 & DAY 0 & DAY 7 \\
\hline Control & $1.4 \pm 0.082^{b}$ & $1.6 \pm 0.163^{b}$ & $0.088 \pm 0.0009^{a}$ & $0.117 \pm 0.012^{a}$ \\
\hline T30 & $0.73 \pm 0.047^{a}$ & $0.63 \pm 0.047^{a}$ & $0.190 \pm 0.007^{b}$ & $0.196 \pm 0.017^{\circ}$ \\
\hline T60 & $0.73 \pm 0.047^{a}$ & $0.6 \pm 0.082^{a}$ & $0.180 \pm 0.006^{b}$ & $0.154 \pm 0.006^{b}$ \\
\hline UV15 & $6.67 \pm 0.558^{b}$ & $8.07 \pm 0.309^{c}$ & $0.095 \pm 0.006^{a}$ & $0.097 \pm 0.004^{a}$ \\
\hline UV30 & $5.9 \pm 0.455^{b}$ & $7.57 \pm 0.249^{c}$ & $0.091 \pm 0.001^{\mathrm{a}}$ & $0.096 \pm 0.001^{a}$ \\
\hline UV60 & $7.03 \pm 0.403^{b}$ & $7.8 \pm 0.245^{c}$ & $0.125 \pm 0.003^{\mathrm{ab}}$ & $0.106 \pm 0.002^{a}$ \\
\hline
\end{tabular}

Table 4. Effects of thermal treatment and UV-C treatment on carotenoid content and ascorbic acid content of juice blend

\begin{tabular}{|c|c|c|c|c|}
\hline \multirow{2}{*}{ Samples } & \multicolumn{2}{|c|}{ Total carotenoid content $\mathbf{( m g / m l )}$} & \multicolumn{2}{|c|}{ Ascorbic acid content (mg/100 ml) } \\
\hline & DAY 0 & DAY 7 & DAY 0 & $88.09 \pm 3.37^{\mathrm{a}}$ \\
\hline Control & $0.31 \pm 0.01^{\mathrm{ab}}$ & $0.44 \pm 0.06^{\mathrm{a}}$ & $102.38 \pm 6.73^{\mathrm{b}}$ & $83.33 \pm 8.91^{\mathrm{a}}$ \\
\hline T30 & $0.77 \pm 0.02^{\mathrm{c}}$ & $0.27 \pm 0.04^{\mathrm{a}}$ & $50.52 \pm 7.14^{\mathrm{ab}}$ & $92.86 \pm 5.83^{\mathrm{a}}$ \\
\hline T60 & $0.70 \pm 0.03^{\mathrm{bc}}$ & $0.43 \pm 0.12^{\mathrm{a}}$ & $48.33 \pm 3.37^{\mathrm{ab}}$ & $76.19 \pm 3.37^{\mathrm{a}}$ \\
\hline UV15 & $0.26 \pm 0.01^{\mathrm{a}}$ & $0.35 \pm 0.01^{\mathrm{a}}$ & $57.14 \pm 5.83^{\mathrm{ab}}$ & $76.19 \pm 6.73^{\mathrm{a}}$ \\
\hline UV30 & $0.57 \pm 0.02^{\mathrm{ab}}$ & $0.38 \pm 0.02^{\mathrm{a}}$ & $52.38 \pm 3.37^{\mathrm{ab}}$ & $82.14 \pm 3.57^{\mathrm{a}}$ \\
\hline UV60 & $0.32 \pm 0.03^{\mathrm{a}}$ & $0.42 \pm 0.22^{\mathrm{a}}$ & $55.19 \pm 6.73^{\mathrm{a}}$ & \\
\hline Values followed by different letters within the same column are significantly different $(\mathbf{p}<0.05)(\mathrm{n}=9)$. & & \\
\end{tabular}

clarity in thermal treated juice samples. Clarity of juice samples treated with UV-C exhibited no significant changes. This is agreeable to the work done by Shamsudin, et al. [26], where pineapple juice processed with UV-C exhibited no changes in particle size, thus clotting of colloidal materials were avoided, leading to unchanged viscosity of UV-C processed juice.

A significant increase in NEBI was observed in thermal treated samples while samples treated with UV-C showed no-significant increase. NEBI is an indicator of the browning of juice due to Maillard reaction, consequently leading to changes in colour and nutrient loss [7]. Non-enzymatic browning is usually initiated at high temperature conditions. These conditions accelerate brown pigment formation, thus darkening the juice. A study by Aguilo-Aguayo, et al. [27] showed significant browning in thermal pasteurized strawberry juice. Noci, et al. reported a large difference in NEBI values in thermal treated juice while UV-C treated samples exhibited minor differences relative to untreated juice [28]. This suggests the ability of UV processing to retain similar characteristics with untreated juice.

\section{Total carotenoid content}

UV-C treated samples showed an increase in carotenoid content (Table 4), with UV30 exhibiting an enhancement of $84 \%$ of carotenoid extracted, and an enhancement of 3\% for UV60. This shows that carotenoids were still stable after 30 and 60 minutes of exposure to UV-C. An improvement of carotenoid extraction may be due to the inactivation of enzymes (caused by alteration of DNA by UV photons) responsible for carotenoid degradations [10]. After storage for 7 days, the highest increase (35\%) in carotenoids extracted was observed in UV15 sample, while thermal treated samples exhibited reduction in carotenoid content.

Certain types (or isomers) of carotenoid may be differently affected by storage time. According to Chen, et al. the concentration of carotenoid (13-cis-lutein) increased during storage for 3 months [29]. However, a decrease in total carotenoid content was shown in untreated blend of fruit juicesoymilk as storage time increased [30]. Control had significantly higher carotenoid content compared to both thermal and UV-C treated juice sample, which could be a result of the heat and light sensitive characteristics of carotenoid [31,32].

\section{Ascorbic acid content}

After both treatments, a significant reduction of ascorbic acid content was shown in juice samples in comparison with control (Table 4). UV15 sample exhibited the least reduction of ascorbic acid content (44\%) whereas T60 sample showed the highest reduction (53\%). Ascorbic acid is a lightsensitive compound and is important in fresh juices due to its antioxidant ability. Ascorbic acid content was greatly reduced upon thermal pasteurization, as it is a thermolabile bioactive compound [33]. Based on a previous study, high temperature was found to highly affect ascorbic acid degradation through an aerobic pathway [34]. Similarly, Pala and Toklucu observed a significant degradation of ascorbic acid in thermal pasteurized orange juice, due to its heat sensitive characteristics [35]. The loss of ascorbic acid after UV-C processing is considered normal due to its characteristics that is the strongest absorber of UV-C light [1]. However, juice processed with UV-C retained a higher amount of ascorbic acid compared to heat pasteurized juice throughout storage period. Enhancement in antioxidant activity including ascorbic acid content may occur in UV-C treated juice, as observed in 'Golden Delicious' apples exposed to UV-C which contain higher ascorbic acid content compared to untreated samples after storage for 30 days (Lee and Coates, 2003).

\section{Antioxidant activity (TPC, TFC, TAC, and DPPH radical scavenging activity assay)}

The effects of thermal and UV-C treatment on antioxidant activity of juice blend are shown in Table 5. A significant enhancement in extractability of phenolic compounds by UV-C treatment was observed, where UV30 (50.43 mg GAE/100 ml) exhibited the highest amount of phenolic compounds extracted compared to control $(31.23 \mathrm{mg}$ GAE$/ 100 \mathrm{ml})$. Exposure of UV-C may contribute to increase enzyme phenylalanine lyase activity, which then contributes to activation of phenolic 
Table 5. Effects of thermal treatment and UV-C treatment on total polyphenol content, DPPH radical scavenging activity, total antioxidant capacity and total flavonoid content of juice blend.

\begin{tabular}{|c|c|c|c|c|c|c|c|c|}
\hline \multirow[t]{2}{*}{ Samples } & \multicolumn{2}{|c|}{ TPC (mg GAE/100 ml) } & \multicolumn{2}{|c|}{ DPPH ( $\mu \mathrm{g}$ AAE/ml) } & \multicolumn{2}{|c|}{ TAC ( $\mu \mathrm{g} \mathrm{AAE} / \mathrm{ml})$} & \multicolumn{2}{|c|}{ TFC (mg CE/100ml) } \\
\hline & DAY 0 & DAY 7 & DAY 0 & DAY 7 & DAY 0 & DAY 7 & DAY 0 & DAY 7 \\
\hline Control & $31.23 \pm 2.05^{\mathrm{a}}$ & $39.17 \pm 1.18^{a}$ & $96.46 \pm 0.17^{a}$ & $96.77 \pm 0.11^{\mathrm{a}}$ & $136.95 \pm 1.58^{a}$ & $122.41 \pm 8.15^{\mathrm{ab}}$ & $1.21 \pm 0.37^{a}$ & $0.96 \pm 0.80^{\mathrm{a}}$ \\
\hline T30 & $39.21 \pm 3.48^{\mathrm{abc}}$ & $39.33 \pm 2.45^{\mathrm{a}}$ & $95.49 \pm 1.04^{a}$ & $96.56 \pm 0.19^{a}$ & $123.52 \pm 5.00^{\mathrm{b}}$ & $154.38 \pm 5.46^{c}$ & $1.05 \pm 0.15^{\mathrm{a}}$ & $1.18 \pm 0.29^{a}$ \\
\hline T60 & $35.91 \pm 1.21^{\mathrm{ab}}$ & $38.41 \pm 0.44^{a}$ & $93.81 \pm 1.63^{b}$ & $96.81 \pm 0.11^{a}$ & $141.70 \pm 15.74^{a}$ & $185.7 \pm 19.63^{d}$ & $1.06 \pm 0.17^{a}$ & $0.71 \pm 0.09^{a}$ \\
\hline UV15 & $41.83 \pm 1.31^{\mathrm{bcd}}$ & $47.04 \pm 4.03^{\mathrm{a}}$ & $96.29 \pm 0.26^{a}$ & $97.14 \pm 0.11^{b}$ & $141.2 \pm 8.98^{a}$ & $146.50 \pm 8.70^{\mathrm{a}}$ & $1.05 \pm 0.10^{\mathrm{a}}$ & $0.6 \pm 0.32^{\mathrm{a}}$ \\
\hline UV30 & $50.43 \pm 3.93^{d}$ & $47.48 \pm 3.78^{a}$ & $94.51 \pm 1.03^{a}$ & $96.82 \pm 0.10^{\mathrm{a}}$ & $133.43 \pm 3.99^{a}$ & $146.21 \pm 10.84^{a}$ & $1.46 \pm 0.51^{\mathrm{a}}$ & $0.85 \pm 0.71^{a}$ \\
\hline UV60 & $46.51 \pm 4.17^{\mathrm{cd}}$ & $46.25 \pm 2.74^{\mathrm{a}}$ & $94.62 \pm 1.57^{a}$ & $96.74 \pm 0.27^{a}$ & $147.04 \pm 3.34^{\mathrm{a}}$ & $137.69 \pm 19.17^{a}$ & $1.6 \pm 0.83^{a}$ & $1.08 \pm 0.18^{a}$ \\
\hline
\end{tabular}

Values followed by different letters within the same column are significantly different $(p<0.05)(n=9)$.

\section{Sensory Analysis}

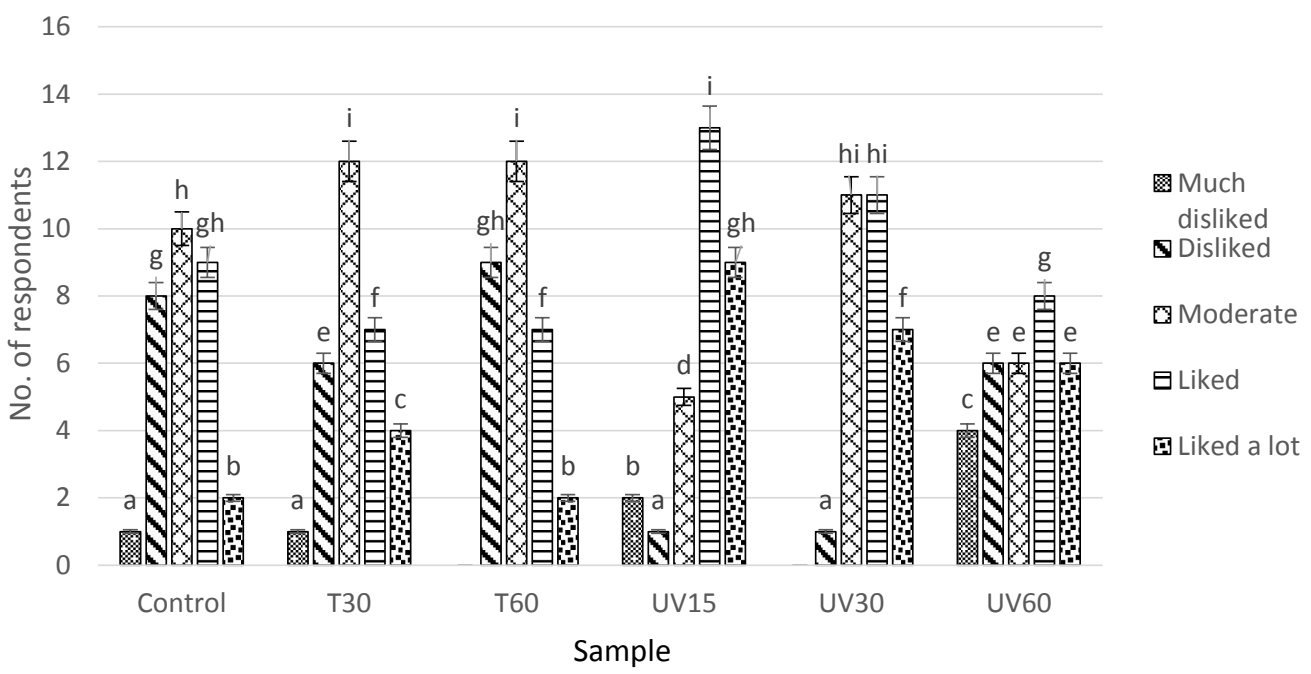

Figure 1. Effects of thermal treatment and UV-C treatment on sensory evaluation of juice blend.

biosynthesis pathway, thus leading to enhancement of phenolic compounds [36]. Further degradation of polyphenols is avoided as UV-C promotes inactivation of polyphenol oxidase [1]. On the other hand, thermal treatment also resulted in an increase in total phenolic content, T30 $(25.6 \%)$ and T60 (15\%). The total polyphenol content in all treated samples showed no significant difference after storage. This is similar to a study conducted by Goh. et al. that observed no significant difference in total polyphenol content of pineapple juice treated with thermal and UV-C after storage for 2 weeks [37]. The enzyme that degrades phenolic compound, peroxidase, were inactivated thus maintaining the phenolic compound throughout storage [33]. A similar trend was observed in the total antioxidant capacity of treated samples. Except for T30 on day 0, all treated samples exhibited an increase in TAC after storage. The increase in antioxidant capacity may be due to increase of polyphenolic compounds in the juice blend as a result of enzyme activation as discussed earlier. Nevertheless, after storage the DPPH activity in T30 increased to be similar to the control. No significant changes were observed in total flavonoid content of all samples after treatment and after storage. In contrast, an increase in flavonoid has been reported after UV-C treatment. This could be a defensive response to the development of free radicals, which is triggered by UV-C light exposure which subsequently initiates the accumulation of phytoalexins and other stress responses [36].

\section{Sensory analysis}

Control was positioned in moderate scale, while 'liked' and 'liked a lot' scale were observed higher in UV-C treated samples compared to thermal treated samples (Figure 1). Thermal treatment was also positioned in moderate scale, with T60 obtaining a highest 'disliked' rate. From the results, T60 sample falls in the highest 'disliked' scale. This is similar to Sentandreu, et al. who reported a decrease in taste of fruit juice heated above $70^{\circ} \mathrm{C}$ [38]. On the other hand, UV-C treated samples obtained a higher score for 'liked' and 'liked a lot' scale. Overall, juice blend treated with UV-C exhibited no significant changes in taste and was accepted by most panellists.

\section{Conclusions}

Both thermal treatment and UV-C treatment successfully extended the shelf life of juice blend. However, thermal treatment resulted in poorer visual quality where clarity was compromised as well as significant reduction in carotenoid and ascorbic acid, both which are important nutritional characteristics of juice. Furthermore, thermal treated juice was least accepted by consumers compared to control and UV-treated samples. UV-C on the other hand had better retention of physicochemical and nutritional quality and received the highest preference by consumers. As a conclusion, all results showed the potential use of UV-C in extending shelf life of juice blend as well as maintaining the quality of juice blend.

\section{Acknowledgements}

The authors would like to thank the CEBAR RU006 - 2017 grant for supporting this research. 
Citation: Nornisa N, Somasundram C, Razali Z. The effects of UV-C treatment on the quality of orange, carrot and celery juice blend. J Food Sci Nutr. 2018;1(3):1-7.

\section{References}

1. Abdul Karim S, Shamsudin N, Abdul Rahman R, et al. Fruit Juice Production Using Ultraviolet Pasteurization: A Review. Beverages. 2016;2(3):1-22.

2. De Carvalho JM, Maia GA, De Figueiredo RW, et al. Development of ablended non-alcoholic beverage composed of coconut water and cashew apple juice containing caffeine. Journal of Food Quality. 2007;30(5):664-81.

3. Raffo A, Sinesio F, Moneta E, et al. Internal quality of fresh and cold stored celery petioles described by sensory profile, chemical and instrumental measurements. European Food Research and Technology. 2006;222(5-6):590-9.

4. Rawson A, Patras A, Tiwari, BK. Effect of thermal and nonthermal processing technologies on the bioactive content of exotic fruits and their products: Review of recent advances. Food Research International. 2011;44(7):1875-87.

5. Pala CU, Toklucu AK. Microbial, physicochemical and sensory properties of UV-C processed orange juice and its microbial stability during refrigerated storage. LWT - Food Science and Technology. 2013;50:426-31.

6. Zhang $\mathrm{C}$, Trierweiler $\mathrm{B}, \mathrm{Li} \mathrm{W}$, et al. Comparison of thermal, ultraviolet- $\mathrm{C}$, and high pressure treatments on quality parameters of watermelon juice. Food Chemistry. 2011;126:254-60.

7. Koutchma T, Popovic V, Ros-Polski V, et al. Effects of Ultraviolet Light and High-Pressure Processing on Quality and Health-Related Constituents of Fresh Juice Products. Comprehensive Reviews in Food Science and Food Safety. 2016;15(5):844-67.

8. Santhirasegaram V, Razali Z, George DS, et al. Comparison of UV-C treatment and thermal pasteurization on quality of Chokanan mango (Mangifera indica L.) juice. Food and Bioproducts Processing. 2015;94:313-21.

9. Santhirasegaram V, Razali Z, Somasundram C. Effects of thermal treatment and sonication on quality attributes of Chokanan mango (Mangifera indica L.) juice. Ultrasonics Sonochemistry. 2013;20(5):1276-82.

10. Glevitzky MI, Pop M, Brusturean GA, et al. Efficient use of antioxidants to preserve fruit juice. Rev Chem. 2008;59:1291-5

11. Cohen E, Birk Y, Mannheim $\mathrm{CH}$, et al. A rapid method to monitor quality of apple juice during thermal processing. LWT-Food Science and Technology. 1998;31(7-8):612-6.

12. Ranganna S. Manual of analysis of fruit and vegetable products. 1997.

13. Lee HS, Castle WS, Coates GA. High-performance liquid chromatography for the characterization of carotenoids in the new sweet orange (Earlygold) grown in Florida, USA. Journal of Chromatography A. 2001;913(1):371-7.

14. Scott KJ. Detection and measurement of carotenoids by UV/VIS spectrophotometry. Current protocols in food analytical chemistry. 2001.
15. Xu G, Liu D, Chen J, et al. Juice components and antioxidant capacity of citrus varieties cultivated in China. Food chemistry. 2008;106(2):545-51.

16. Bae SH, Suh HJ. Antioxidant activities of five different mulberry cultivars in Korea. LWT-Food Science and Technology. 2007;40(6):955-62.

17. Prieto P, Pineda M, Aguilar M. Spectrophotometric quantitation of antioxidant capacity through the formation of a phosphomolybdenum complex: specific application to the determination of vitamin E. Analytical biochemistry. 1999;269(2):337-41.

18. Sakanaka, S, Tachibana Y, Okada Y. Preparation and antioxidant properties of extracts of Japanese persimmon leaf tea (kakinoha-cha). Food chemistry. 2005;89(4):56975 .

19. Bull M, Zerdin M, Howe E, et al. The effect of high pressure processing on the microbial, physical and chemical properties of Valencia and Navel orange juice. Innovative Food Science and Emerging Technologies. 2004;5(2):13549.

20. Chia SL, Shamsudin R, Mohd Adzahan N, et al. The effect of storage on the quality attributes of ultraviolet-irradiated and thermally pasteurised pineapple juices. International Food Research Journal. 2012;19(3):1001-10.

21. Rivas A, Rodrigo D, Martínez A, et al. Effect of PEF and heat pasteurization on the physical-chemical characteristics of blended orange and carrot juice. LWT-Food Science and Technology. 2006;39(10):1163-70.

22. Vandresen S, Quadri MG, de Souza JA, et al. Temperature effect on the rheological behaviour of carrot juices. Journal of Food Engineering. 2009;92(3):269-274.

23. Yeom HW, Streaker CB, Zhang QH, et al. Effects of pulsed electric fields on the quality of orange juice and comparison with heat pasteurization. Journal of Agricultural and Food Chemistry. 2000;48(10):4597-605.

24. WA, Smith PG, Morris AEJ. Production and quality of tomato concentrates. Critical Reviews in Food Science and Nutrition. 1998;38(7):537-64.

25. Aguilo-Aguayo I, Soliva-Fortuny R, Martin-Belloso O. Color and viscosity of watermelon juice treated by highintensity pulsed electric fields or heat. Innovative food science \& emerging technologies. 2010;11(2):299-305.

26. Shamsudin R, Ling CS, Adzahan NM, et al. Rheological properties of ultraviolet-irradiated and thermally pasteurized Yankee pineapple juice. Journal of Food Engineering. 2013;116(2):548-53.

27. Aguilo A, Oms-Oliu G, Soliva-Fortuny R, et al. Changes in quality attributes throughout storage of strawberry juice processed by highintensity pulsed electric fields or heat treatments. LWT- Food Science and Technology. 2009;42:813-8.

28. Noci F, Riener J, Walkling-Ribeiro M, et al. Ultraviolet irradiation and pulsed electric fields (PEF) in a hurdle 
strategy for the preservation of fresh apple juice. Journal of food engineering. 2008;85(1):141-6.

29. Chen HE, Peng HY, Chen BH. Stability of carotenoids and vitamin A during storage of carrot juice. Food Chemistry. 1996;57(4):497-503.

30. Morales-de La Peña M, Salvia-Trujillo L, Rojas-Graü MA, et al. Changes on phenolic and carotenoid composition of high intensity pulsed electric field and thermally treated fruit juice-soymilk beverages during refrigerated storage. Food chemistry. 2001;129(3):982-90.

31. Gama JJT, Sylos CM. Effect of thermal pasteurization and concentration on carotenoid composition of Brazilian Valencia orange juice. Food Chemistry. 2007;100:1686-90.

32. Lee HS, Coates GA. Effect of thermal pasteurization on Valencia orange juice colour and pigments. Food Science and Technology. 2003;36:153-6.

33. Odriozola-Serrano I, Soliva-Fortuny R, Martín-Belloso O. Changes of health-related compounds throughout cold storage of tomato juice stabilized by thermal or high intensity pulsed electric field treatments. Innovative Food Science \& Emerging Technologies. 2008;9(3):272-9.
34. Oms-Oliu G, Odriozola-Serrano I, Martín-Belloso O. The effects of non-thermal technologies on phytochemicals. INTECH Open Access Publisher. 2012.

35. Pala CU, Toklucu AK. Effect of UV-C light on anthocyanin content and other quality parameters of pomegranate juice. Journal of Food Composition and Analysis. 2001;4:790-5.

36. Alothman M, Bhat R, Karim AA. Effects of radiation processing on phytochemicals and antioxidants in plant produce. Trends in Food Science \& Technology. 2009;20(5):201-12.

37. Goh SG, Mohd Adzahan N, Leong CM, et al. Effect of thermal and ultraviolet treatments on the stability of antioxidant compounds in single strength pineapple juice throughout refrigerated storage. International Food Research Journal. 2012;19(3):1131-6.

38. Sentandreu E, Carbonell L, Carbonell JV, et al. Effects of heat treatment conditions on fresh taste and on pectinmethylesterase activity of chilled mandarin and orange juices. Food Science and Technology International. 2005;11(3):217-22.

\section{*Correspondence to:}

Chandran Somasundram

Associate Professor

Biotechnology Division

Institute of Biological Sciences

Faculty of Science

University of Malaya

Malaysia

Tel: +603-79674423;+6012-2320180

E-mail: chandran@um.edu.my 